УДК 621.396

DOI: https://doi.org/10.26642/ten-2020-2(86)-108-116

\author{
А.В. Булашенко, ст. викладач \\ С.I. Пільтяй, к.т.н., доц. \\ Є.I. Калініченко, студентка \\ Національний технічний університет Украӥни \\ «КПI імені Ігоря Сікорського» \\ О.В. Булашенко, студент
}

Хіміко-технологічний коледж Сумського державного університету

\title{
Регульований поляризатор на основі квадратного хвилеводу із діафрагмами та штирями
}

\begin{abstract}
Поляризаџійне оброблення сигналів широко застосовується у сучасних інформаційних та телекомунікаиійних системах різного призначення. Оброблення поляризачії сигналів здійснюється в поляризаційно-адаптивних антенних системах. Ключовим елементом таких систем є пристрої трансформування та оброблення поляризації. Вони здійснюють перетворення видів поляризаиії та розділяють різні види між собою. Найбільш поширеними $\epsilon$ системи, щзо використовують одну колову поляризацію або дві ортогональні колові поляризачії одночасно. Відсутність необхідності чіткої орієнтації за кутом між передавальною та приймальною антенами для встановлення зв'язку є однією із базових переваг такого виду поляризації. За використання антенних систем із лінійною поляризацією з'являються втрати сигналу внаслідок неузгодження орієнтації площзин поляризаџії передавальної та приймальної антен. Ця особливість колової поляризації є важливою для супутникових та багатьох інших телекомунікаційних систем. У таких системах складно забезпечити фіксовану орієнтацію однієї антени відносно іншої. Крім того, колова поляризація використовується для зв'язку зі супутниками, щзо обертаються навколо напрямку радіолінії. Незалежно від орієнтації антени nід час використання колової поляризації рівень прийнятого сигналу є постійним. Ці переваги пояснюють, чому антени із коловою поляризачією широко застосовуються в радіотехнічних системах різного призначення.

У роботі представлено результати розробки поляризачійного пристрою на основі квадратного хвилеводу із двома штирями та двома діафрагмами у діапазоні частот від 7,7 до 8,5 ГГц. Стаття містить результати розрахунків за допомогою розробленої математичної моделі пристрою. Крім того, для порівняння наведено результати моделювання пристрою за допомогою методу скінченних елементів. Було порівняно поляризаційні характеристики та узгодження розробленого поляризатора. Створена математична модель дає можливість ефективно аналізувати характеристики при зміні конструкиійних параметрів. До них належать: величина стінки квадратного хвилеводу, висота діафрагм та штирів, відстань між ними, товщина діафрагм та штирів. Розроблений поляризатор призначений для застосування 8 супутникових телекомунікаційних та радарних системах.

Ключові слова: поляризатор; діафрагма; итир; хвилевід; коефічієнт еліптичності; кросполяризаиійна розв'язка; диференційний фазовий зсув; коефіиієнт стоячої хвилі за напругою.
\end{abstract}

Актуальність теми. Швидкий розвиток телекомунікаційних супутникових систем та радарів спонукає до збільшення обсягів інформації, яка передається у бездротових каналах. У свою чергу це вимагає вдосконалення існуючих та створення нових методів оброблення сигналів. Поляризаційне оброблення сигналів займає провідне місце серед цих методів. Адаптивні антенні системи, що здійснюють таку обробку, містять хвилевідні поляризатори та ортомодові перетворювачі. Електромагнітні характеристики таких пристроїв визначають загальні поляризаційні характеристики антенної системи, які дуже чутливі до неточностей виготовлення. Таким чином, точне математичне моделювання та оптимізація електромагнітних характеристик є важливим завданням для створення сучасних хвилевідних поляризаторів.

Аналіз останніх досліджень та публікацій, на які спирається автор. Велика кількість різноманітних поляризаційних пристроїв використовується в радарних пристроях військового та цивільного призначення. Крім того, великого поширення поляризатори набули в сучасних супутникових телекомунікаційних системах. Хвилевідні поляризатори створюють на основі круглих [1-3], прямокутних [4-6] або коаксіальних структур [7-8]. Поляризаційні пристрої розробляють на основі неоднорідностей у хвилеводах. Існують структури поляризаторів на основі неоднорідностей у вигляді діафрагм [9-12], штирів [13-14], перегородок [15-20] та гофрувань [21-22]. Також існує низка конструкцій хвилевідних поляризаторів із неоднорідностями у вигляді діафрагм із вузькими щілинами [23-24]. 
Усі розглянуті структури мають однаковий недолік, що полягає у складності конструкції, обмеженій смузі пропускання, відхиленні характеристик від теоретичних унаслідок неточностей виготовлення та неможливості точного налаштування характеристик після виготовлення. Тому в цій роботі запропоновано конструкцію поляризатора, що містить два типи неоднорідностей у хвилеводі діафрагми та штирі. Наявність діафрагм у конструкції дозволяє забезпечити широку робочу смугу частот. Присутність у конструкції штирів гарантує можливість налаштування хвилевідного поляризатора після його виготовлення.

Метою статті $є$ оптимізація електромагнітних характеристик поляризатора на основі квадратного хвилеводу із діафрагмами та штирями за рахунок зміни розмірів його конструкції.

Викладення основного матеріалу. Конструкцію хвилевідного поляризатора зображено на рисунку 1. Конструкція містить дві діафрагми висотою $h$ та товщиною $w$, два штирі висотою $h_{p}$ та діаметром $d$. Відстань між діафрагмою та штирем становить $l$.
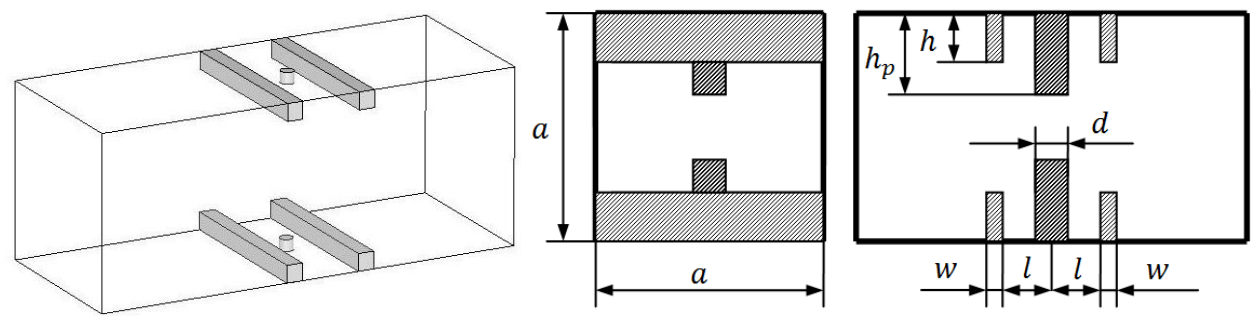

Рис. 1. Конструкція поляризатора

Така конструкція забезпечує основні поляризаційні характеристики. Циліндричний штир забезпечує настройку та підстроювання характеристик за рахунок зміни довжини штиря у хвилеводі.

За теорією мікрохвильових кіл зобразимо схему у вигляді окремих структурних схем, тобто розіб'ємо їі на елементарні чотириполюсники (рис. 2). На рисунку 2, а зображена структурна схема хвилевідного поляризатора зі штирем та індуктивними діафрагмами, що увімкнені паралельно. На рисунку 2, б подана загальна структурна схема хвилевідного поляризатора зі штирем та ємнісними діафрагмами, що увімкнені паралельно.

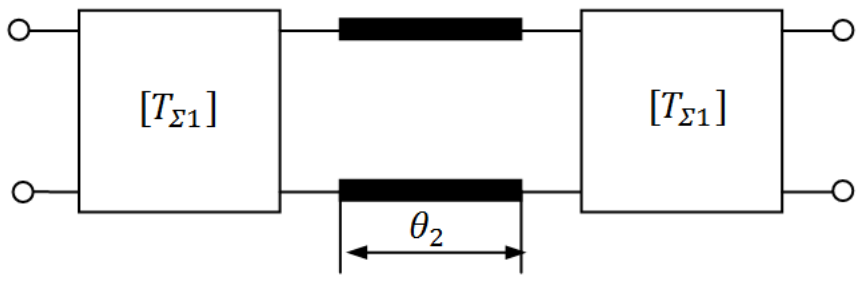

$a$

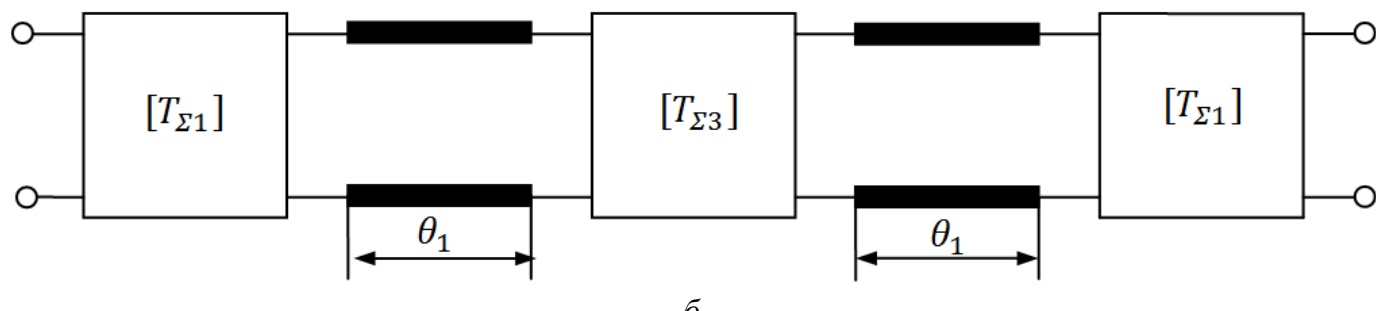

$\sigma$

Рис. 2. Структурна схема: а-моделі з індуктивними діафрагмами та итирем; б-моделі із смнісними діафрагмами та штирем

Визначимо загальну хвильову матрицю розсіювання через елементи загальної хвильової матриці передачі:

$$
\left[S_{\Sigma}\right]=\left[\begin{array}{ll}
S_{11 \Sigma} & S_{12 \Sigma} \\
S_{21 \Sigma} & S_{22 \Sigma}
\end{array}\right]=\frac{1}{T_{11 \Sigma}}\left[\begin{array}{cc}
T_{21 \Sigma} & |T| \\
1 & -T_{12 \Sigma}
\end{array}\right],
$$

де $|T|$ - визначник хвильової матриці передачі. 
Для моделі з індуктивними діафрагмами та штирем загальна хвильова матриця передачі визначається виразом:

$$
\left[T_{\Sigma}\right]=\left[\begin{array}{ll}
T_{11 \Sigma} & T_{12 \Sigma} \\
T_{21 \Sigma} & T_{22 \Sigma}
\end{array}\right]=\left[T_{1}\right] \cdot\left[T_{2}\right] \cdot\left[T_{3}\right]
$$

де $\left[T_{1}\right],\left[T_{3}\right]$ - матриці, що описують діафрагми; $\left[T_{2}\right]$ - матриця, що описує відрізок регулярної лінії передачі.

Хвильові матриці передачі визначаються:

$$
\left[T_{1}\right]=\left[T_{3}\right]=\left[\begin{array}{ll}
T_{11} & T_{12} \\
T_{21} & T_{22}
\end{array}\right],\left[T_{2}\right]=\left[\begin{array}{cc}
e^{j \theta_{2}} & 0 \\
0 & e^{-j \theta_{2}}
\end{array}\right],
$$

де $\theta_{2}$ - електрична довжина регулярної лінії передачі.

Електрична довжина регулярної лінії передачі:

$$
\theta_{2}=2 \theta_{1}=\frac{4 \pi l}{\lambda_{x B}},
$$

де $\lambda_{x в}-$ довжина хвилі у хвилеводі.

Для моделі з ємнісними діафрагмами та штирем загальна хвильова матриця передачі визначається виразом:

$$
\left[T_{\Sigma}\right]=\left[\begin{array}{ll}
T_{11 \Sigma} & T_{12 \Sigma} \\
T_{21 \Sigma} & T_{22 \Sigma}
\end{array}\right]=\left[T_{1}\right] \cdot\left[T_{2}\right] \cdot\left[T_{3}\right] \cdot\left[T_{4}\right] \cdot\left[T_{5}\right],
$$

де $\left[T_{1}\right],\left[T_{5}\right]$ - матриці, що описують діафрагму у хвилеводі; $\left[T_{3}\right]$ - матриця, що описує штир у хвилеводі; $\left[T_{2}\right],\left[T_{4}\right]$ - матриці, що описують відрізок регулярної лінії передачі.

Хвильові матриці передачі визначаються:

$$
\left[T_{1}\right]=\left[T_{5}\right]=\left[\begin{array}{ll}
T_{11} & T_{12} \\
T_{21} & T_{22}
\end{array}\right],\left[T_{2}\right]=\left[T_{4}\right]=\left[\begin{array}{cc}
e^{j \theta_{1}} & 0 \\
0 & e^{-j \theta_{1}}
\end{array}\right],\left[T_{3}\right]=\left[\begin{array}{cc}
T_{11}^{\prime} & T_{12}^{\prime} \\
T_{21}^{\prime} & T_{22}^{\prime}
\end{array}\right],
$$

де $\theta_{1}$ - електрична довжина регулярної лінії передачі.

Електрична довжина регулярної лінії передачі:

$$
\theta_{1}=\frac{2 \pi l}{\lambda_{x B}}
$$

де $\lambda_{x в}-$ довжина хвилі у хвилеводі.

Довжина хвилі у хвилеводі:

$$
\lambda_{x \beta}=\frac{\lambda_{0}}{\sqrt{1-\left(\frac{\lambda_{0}}{\lambda_{\kappa p}}\right)^{2}}}
$$

де $\lambda_{0}$ - довжина хвилі у вільному просторі; $\lambda_{\kappa p}-$ критична довжина хвилі.

Хвильова матриця передачі для штиря:

$$
\left[T_{3}\right]=\left[\begin{array}{ll}
T_{11}^{\prime} & T_{12}^{\prime} \\
T_{21}^{\prime} & T_{22}^{\prime}
\end{array}\right]=\left[\begin{array}{cc}
\frac{2+Y_{p}}{2} & \frac{-Y_{p}}{2} \\
\frac{-Y_{p}}{2} & \frac{2-Y_{p}}{2}
\end{array}\right],
$$

де $Y_{p}-$ провідність штиря у хвилеводі.

Провідність штиря у хвилеводі визначається формулою:

$$
Y_{p}=\frac{j \pi \lambda_{0} \lambda_{g}\left[1-\cos \left(k h_{p}\right)\right]^{2}}{a^{2} k(\mathrm{a}-\mathrm{r})\left(2+\cos \left(2 k h_{p}\right)\right)-\ln (\mathrm{a} / \mathrm{r}) \sin \left(2 k h_{p}\right)},
$$

де $a$ - довжина стінки квадратного хвилеводу; $h_{p}$ - висота штиря у хвилеводі; $k$ - хвильове число;

$r$ - радіус штиря.

Для врахування товщини діафрагми використали еквівалентні схеми заміщення (рис. 3). 
Для індуктивної діафрагми реактивні опори еквівалентної схеми (рис. 3, a) визначаються виразами [25]:

$$
X_{a}=\frac{2 a}{\lambda_{x b}} \cdot\left(\frac{a}{\pi \cdot D_{1}}\right)^{2} ; \quad X_{b}=\frac{a}{8 \lambda_{x b}} \cdot\left(\frac{\pi \cdot D_{2}}{a}\right)^{4},
$$

де

$$
D_{1}=\frac{2 h}{\sqrt{2}} \cdot\left[1+\frac{w}{2 \pi h} \cdot \ln \left(\frac{8 \pi h}{e \cdot w}\right)\right] ; \quad D_{2}=\sqrt[4]{\frac{4}{3 \pi} w \cdot(2 h)^{2}} \cdot\left(\frac{\pi \cdot D_{2}}{a}\right)^{4},
$$

де $a$-розмір великої стінки хвилеводу; $w$ - товщина діафрагми; $h$-висота діафрагми.

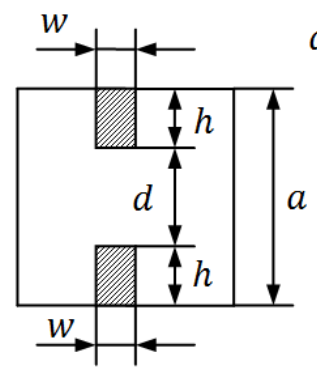

a)

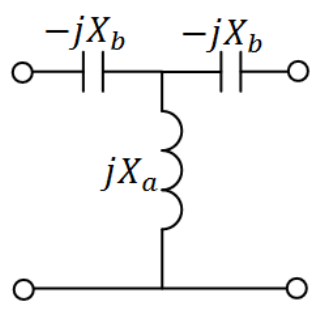

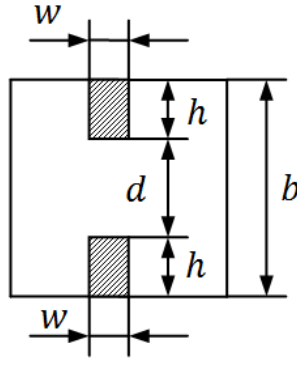

б)

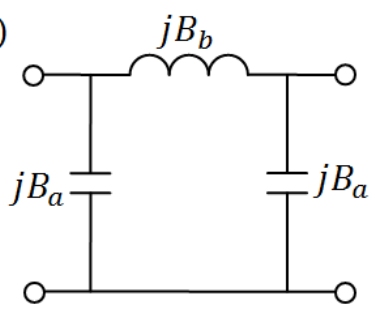

Рис. 3. Еквівалентні схеми заміщення діафрагм: а) індуктивної; б) ємнісної

Для ємнісної діафрагми реактивні провідності еквівалентної схеми (рис. 3, б) визначаються виразами [25]:

$$
B_{a}=B_{1}+\frac{b}{d} \cdot \operatorname{tg}\left(\frac{\pi \cdot w}{\lambda_{x b}}\right), \quad B_{b}=\frac{b}{d} \cdot \csc \left(\frac{2 \pi \cdot w}{\lambda_{x b}}\right),
$$

де

$$
B_{1}=\frac{b}{\lambda_{x b}} \cdot\left[\left(\frac{\pi \cdot 2 h}{2 b} \cdot g\right)+\frac{1}{6}\left(\frac{\pi \cdot 2 h}{2 b} \cdot g\right)-\frac{\pi}{2} \cdot \frac{2 h}{b} \cdot \frac{w}{d}+\frac{3}{2}\left(\frac{b}{\lambda_{x b}}\right)^{2} \cdot\left(\frac{\pi \cdot 2 h}{2 b}\right)^{4}\right],
$$

де

$$
g=1+\frac{w}{\pi \cdot 2 h} \cdot \ln \left(\frac{4 \pi}{e}+\frac{2 h}{w}\right),
$$

де $a$-розмір великої стінки хвилеводу; $w$ - товщина діафрагми; $h$-висота діафрагми.

Характеристиками поляризатора $\epsilon$ фазова, узгоджувальна та поляризаційні. Фазова та узгоджувальна - це диференційний фазовий зсув та коефіцієнт стоячої хвилі за напругою (КСХН). Поляризаційними характеристиками поляризатора $\epsilon$ коефіцієнт еліптичності та кросполяризаційна розв'язка (КПР).

Диференціальний фазовий зсув визначається виразом:

$$
\Delta \varphi=\varphi_{\sum 21 . \mathrm{L}}-\varphi_{\Sigma 21 . C},
$$

де $\varphi_{\sum 21 . \mathrm{L}}-$ фаза параметра $S_{\sum 21 . \mathrm{L}}$ загальної хвильової матриці розсіювання для моделі з індуктивностями; $\varphi_{\sum 21 . C}-$ фаза параметра $S_{\sum 21 . C}$ загальної хвильової матриці розсіювання для моделі з ємностями.

КСХН горизонтальної та вертикальної поляризації визначається формулою

$$
V S W R_{L}=\frac{1+\left|S_{\sum 11 . \mathrm{L}}\right|}{1-\left|S_{\sum 11 . \mathrm{L}}\right|}, V S W R_{C}=\frac{1+\left|S_{\sum 11 . \mathrm{C}}\right|}{1-\left|S_{\sum 11 . \mathrm{C}}\right|} .
$$

Коефіцієнт еліптичності визначається:

$$
r=10 \log \left[\frac{\left|S_{\sum 11 . L}\right|^{2}+\left|S_{\sum 11 . C}\right|^{2}+\sqrt{\left|S_{\sum 11 . L}\right|^{4}+\left|S_{\sum 11 . C}\right|^{4}+2\left|S_{\sum 11 . L}\right|^{2}\left|S_{\sum 11 . C}\right|^{2}}}{\left|S_{\sum 11 . L}\right|^{2}+\left|S_{\sum 11 . C}\right|^{2}-\sqrt{\left|S_{\sum 11 . L}\right|^{4}+\left|S_{\sum 11 . C}\right|^{4}+2\left|S_{\sum 11 . L}\right|^{2}\left|S_{\sum 11 . C}\right|^{2}}}\right] .
$$

КПР розраховується за:

$$
X P D=20 \lg \left[\frac{10^{0.05 r}+1}{10^{0.05 r}-1}\right] .
$$

Дослідимо електромагнітні характеристики математичної моделі хвилевідного поляризатора у Хдіапазоні частот від 7,7 до 8,5 ГГц. 
За допомогою нашої моделі, змінюючи висоту діафрагм $h$ та штиря $h_{p}$, здійснюємо досягнення необхідного диференційного фазового зсуву. Для забезпечення заданого узгодження регулюємо відстань між діафрагмами $l$. Ці зміни необхідно проводити на оптимальній товщині діафрагми. На цій частоті досягаємо оптимального узгодження із невеликим відхиленням диференційного фазового зсуву від $90^{\circ}$.

На рисунку 4 подано характеристики розробленої математичної моделі поляризатора на основі квадратного хвилеводу із двома діафрагмами та двома штирями.

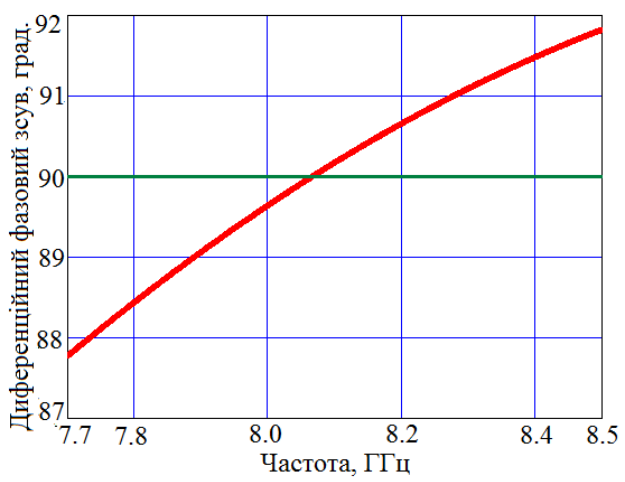

$a$

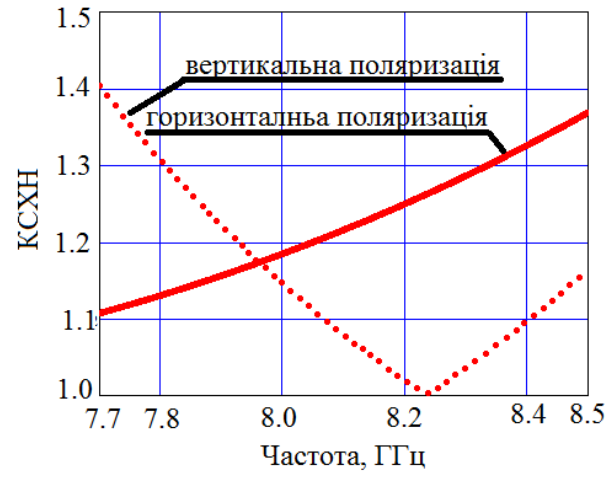

6

Рис. 4. Характеристики математичної моделі: $а$-диференційний фазовий зсув; б - коефіцієнт стоячої хвилі за напругою для обох поляризацій

Рисунок 4, а демонструє, що максимальне відхилення диференційного фазового зсуву від $90^{\circ}$ становить 2,2 ${ }^{\circ}$. Рисунок 4, б показує, що максимальне значення КСХН для обох поляризацій становить величину 1,41 .

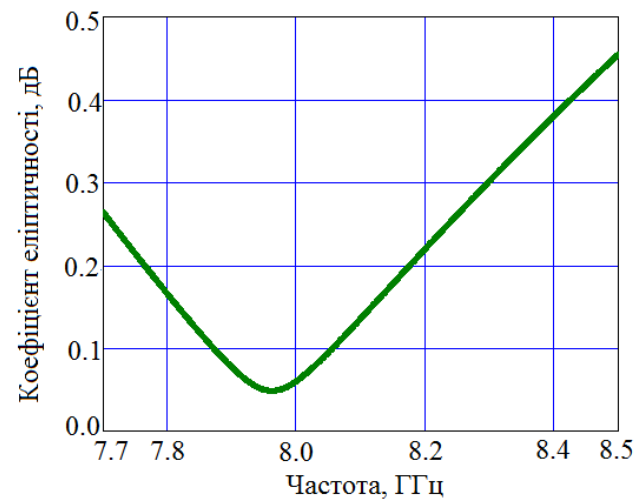

$a$

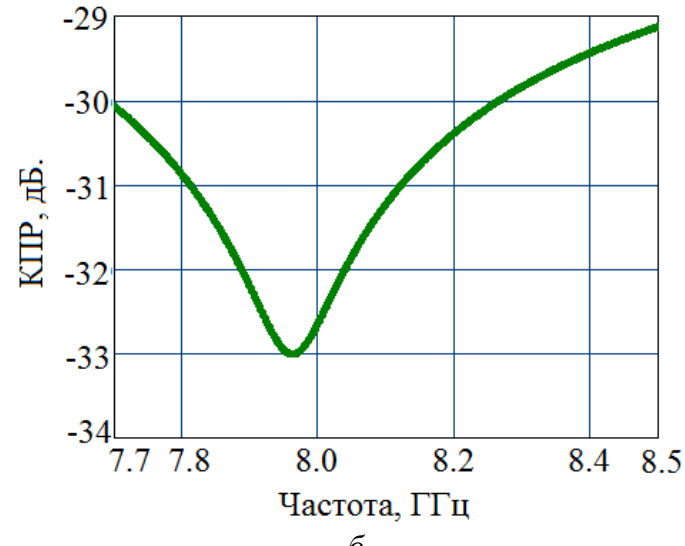

$\sigma$

Рис. 5. Поляризаиійні характеристики математичної моделі

Рисунок 5, а містить залежність коефіцієнта еліптичності від частоти, а рисунок 5, 6 - залежність КПР від частоти. Із рисунку 5 бачимо, що на частоті 8,5 ГГц коефіцієнт еліптичності набуває свого максимального значення - 0,45 дБ. Також на цій частоті КПР набуває максимального значення - 29 дБ.

Дослідимо електромагнітні характеристики числової моделі на основі методу скінченних елементів хвилевідного поляризатора у Х-діапазоні частот від 7,7 до 8,5 ГГц.

На рисунку 6 подано узгоджувальні характеристики поляризатора. Рисунок $6, a$ містить залежність диференційного фазового зсуву від частоти, а рисунок 6, б містить залежність КСХН від частоти у робочому діапазоні частот від 7,7 до 8,5 ГГц досліджуваного прототипу.

Рисунок 6, а демонструє, що максимальне відхилення диференційного фазового зсуву від 90 становить 2,2. Рисунок 6, б показує, що максимальне значення КСВН для обох поляризацій становить величину 1,29 .

На рисунку 7 подано поляризаційні характеристики пристрою у робочому діапазоні частот від 7,7 до 8,5 ГГц. Рисунок 7, $а$ містить залежність коефіцієнта еліптичності від частоти, а рисунок 7, $\sigma$ - залежність КПР від частоти. Із рисунка бачимо, що на частоті 8,45 ГГц коефіцієнт еліптичності набуває свого максимального значення - 0,4 дБ. Також на цій частоті КПР набуває максимального значення - 29 дБ. 


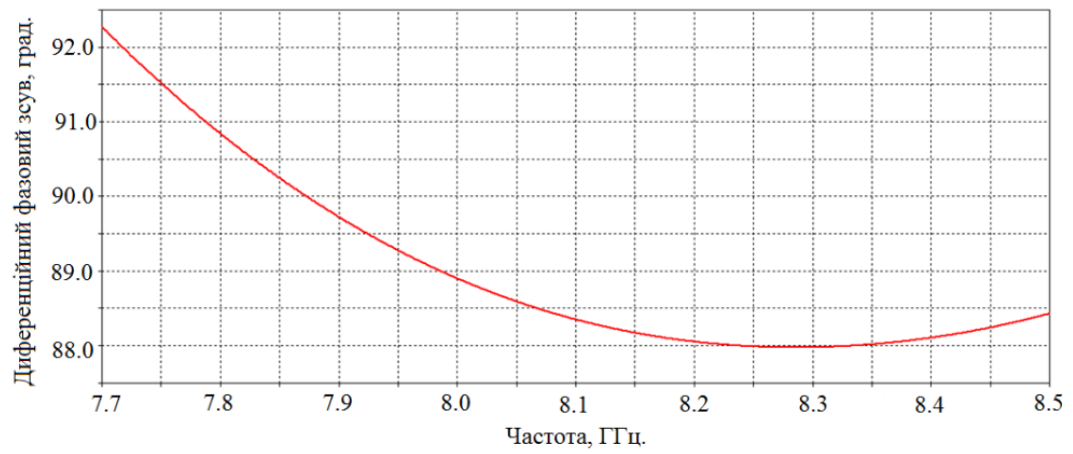

$a$

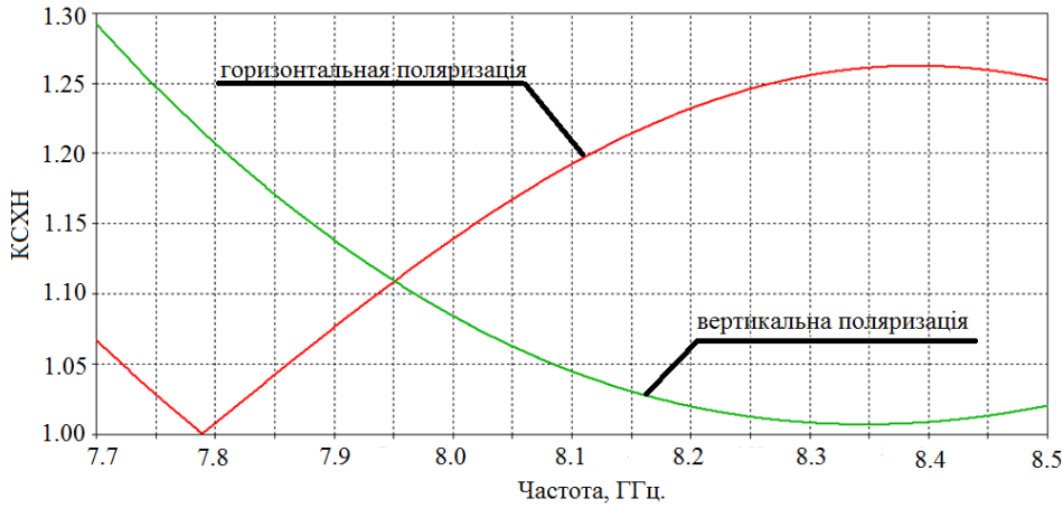

$\sigma$

Рис. 6. Характеристики числового моделювання: $а$-диференційний фазовий зсув; б - коефіиієнт стійної хвилі за напругою для обох поляризаиій
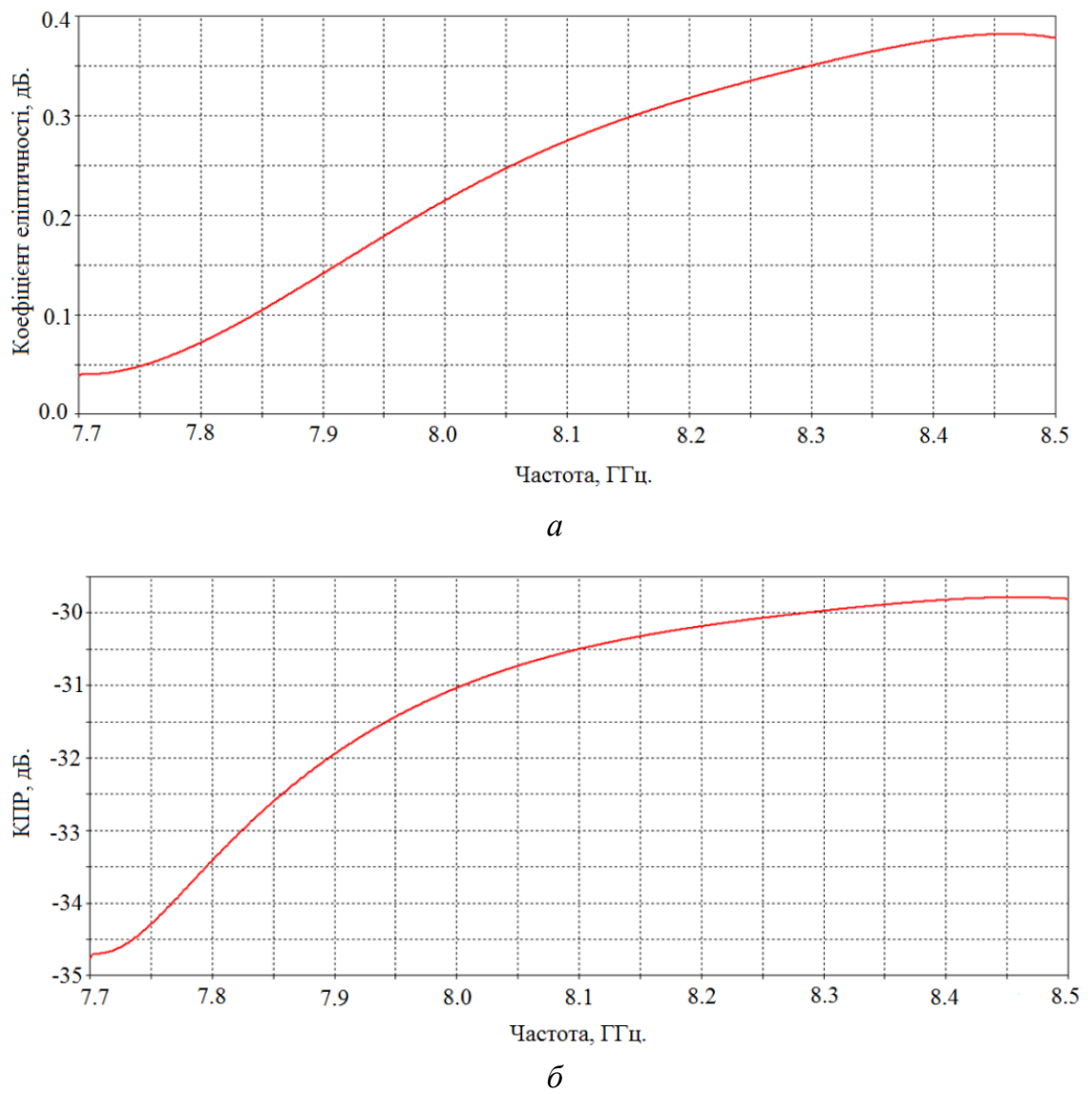

Рис. 7. Поляризаціийні характеристики числової моделі 
Такі розраховані характеристики забезпечують оптимальні розміри конструкції розробленого хвилевідного поляризатора, що подані у таблиці 1.

Розміри оптимальної конструкиії розробленого хвилевідного поляризатора

Таблиияя 1

\begin{tabular}{|c|c|c|c|c|c|}
\hline $\boldsymbol{a}, \boldsymbol{m} \boldsymbol{m}$ & $\boldsymbol{w}, \boldsymbol{m} \boldsymbol{m}$ & $\boldsymbol{l}, \boldsymbol{m} \boldsymbol{m}$ & $\boldsymbol{h}, \boldsymbol{m} \boldsymbol{m}$ & $\boldsymbol{h} \boldsymbol{p}, \boldsymbol{m} \boldsymbol{m}$ & $\boldsymbol{d}, \boldsymbol{m} \boldsymbol{m}$ \\
\hline 28,9 & 3,1 & 5,3 & 2,60 & 2,65 & 2,4 \\
\hline
\end{tabular}

Як бачимо, узгоджувальні та поляризаційні характеристики математичної моделі та числової моделі за методом скінченних елементів збігаються з достатньо високою точністю.

Отже, розроблений хвилевідний поляризатор має досить гарне узгодження та поляризаційні характеристики. Діапазон зміни диференційного фазового зсуву становить $90^{\circ} \pm 2,2^{\circ}$. Поляризатор забезпечує КСХН менше 1,29 для основних мод обох ортогональних поляризацій. Коефіцієнт еліптичності поляризатора не перевищує 0,4 дБ. Кросполяризаційна розв’язка становить 29 дБ.

Висновки та перспективи подальших досліджень. Розроблено нову конструкцію поляризатора на основі квадратного хвилеводу із двома діафрагмами та двома штирями. За допомогою методу еквівалентних мікрохвильових кіл створено точну математичну модель поляризатора. Запропонована модель враховує вплив параметрів конструкції на поляризаційні характеристики i узгодження поляризатора. Створена математична модель враховує вплив на основні характеристики поляризатора висот діафрагм та штирів, відстаней між ними та їх товщини. Розроблена модель дає можливість проводити оптимізацію поляризатора. У роботі виконано оптимізацію конструкції для роботи поляризатора в діапазоні частот від 7,7 до 8,5 ГГц за допомогою зміни геометричних розмірів. Таким чином, модель можна використовувати для створення нових і оптимізації існуючих поляризаторів на основі квадратних хвилеводів із різної кількості діафрагм та штирів. У майбутніх дослідженнях необхідно сфокусуватися на створенні аналітичної моделі, яка дозволятиме враховувати більшу кількість реактивних елементів та більшу кількість хвиль вищих типів. Це дозволить розробити регульовані хвилевідні поляризатори із ширшими робочими смугами частот для антен нових радарів і супутникових інформаційних систем різного призначення.

\section{Список використаної літератури:}

1. A design of novel grooved circular waveguide polarizers / N.Yoneda, R.Miyazaki, I.Matsumura, M.Yamato // IEEE Transactions on Microwave Theory and Techniques. - 2000. - Vol. 48, № 12. - P. 2446-2452.

2. A tunable compact polarizer in a circular waveguide / A.A Kirilenko, S.O. Steshenko, V.N. Derkach, Y.M. Ostryzhnyi // IEEE Transactions on Microwave Theory and Techniques. - 2019. - Vol. 67, № 2. - P. 592-596.

3. Franco M.J. A high-performance dual-mode feed horn for parabolic reflectors with a stepped-septum polarizer in a circular waveguide / M.J. Franco // IEEE Antennas and Propagation Magazine. - 2011. - Vol. 53, № 3. - P. $142-146$.

4. Piltyay S.I. High performance extended C-band 3,4-4,8 GHz dual circular polarization feed system / S.I. Piltyay // XI International Conference on Antenna Theory and Techniques. - Ukraine, Kyiv, 2017. - P. 284-287.

5. Agnihotri I. Design of a compact 3D metal printed Ka-band waveguide polarizer / I.Agnihotri, S.K. Sharma // IEEE Antennas and Wireless Propagation Letters. - 2019. - Vol. 18, № 12. - P. 2726-2730.

6. Combined-phase-shift waveguide polarizer / G.Virone, R.Tascone, O.A. Peverine et al. // IEEE Microwave and Wireless Components Letters. - 2008. - Vol. 18, № 8. - P. 509-511.

7. Dubrovka F.F. A novel wideband coaxial polarizer / F.F. Dubrovka, S.I. Piltyay // IX International Conference on Antenna Theory and Techniques. - Ukraine, Odessa, 2013. - P. 473-474.

8. Stepped approximation technique for designing coaxial waveguide polarizers / A.A. Kirilenko, D.Yu. Kulik, S.A. Pricolotin et al. // IX International Conference on Antenna Theory and Techniques. - Ukraine, Odessa, 2013. P. 470-472.

9. Piltyay S.I. Waveguide iris polarizers for Ku-band satellite antenna feeds / S.I. Piltyay, A.V. Bulashenko, I.V. Demchenko // Journal of Nano- and Electronic Physics. - 2020. - Vol. 12, № 5. - P. 05024-1-05024-5.

10. Bulashenko A.V. Analytical technique for iris polarizers development / A.V. Bulashenko, S.I. Piltay, I.V. Demchenko // IEEE International Conference on Problems of Infocommunications. Science and Technology (PIC S\&T). - Ukraine, Kharkiv, 2020. - P. 471-476.

11. Piltyay S.I. Compact polarizers for satellite information systems / S.I. Piltay, A.V. Bulashenko, I.V. Demchenko // IEEE International Conference on Problems of Infocommunications. Science and Technology (PIC S\&T). Ukraine, Kharkiv, 2020. - P. 317-322.

12. Булашенко А.В. Широкосмугові поляризатори для супутникових інформаційних систем / А.В. Булашенко, C.I. Пільтяй, О.В. Биковський // Матеріали всеукраїнської науково-практичної інтернет-конференції «Молодь в науці: дослідження, проблеми, перспективи». - Вінниця : ВНТУ, 2020. - С. 365-368.

13. Zhu Q.C. Reactance of posts in circular waveguide / O.C. Zhu, A.G. Williamson, M.J. Neve // IEEE Transactions on Microwave Theory and Techniques. - 2007. - Vol. 55, № 8 - P. 1685-1688.

14. Spectral properties of a rectangular wave guiding involving a pair of rectangular posts of equal heights / L.P. Mospan, A.A. Kirilenko, D.Yu. Kulik, S.A. Prikolotin // Telecommunications and Radio Engineering. - 2014. Vol. 73, № 1. - P. 1-17. 
15. Deutschmann B. Broadband septum polarizer with triangular common port / B.Deutschmann, A.F. Jacob // IEEE Transactions on Microwave Theory and Techniques. - 2020. - Vol. 68, № 2. - P. 693-700.

16. Optimum septum polarizer design for various fractional bandwidths / F.F. Dubrovka, S.I. Piltyay, R.R. Dubrovka et al. // Radioelectronics and Communications Systems. - 2020. - Vol. 63, № 1. - P. 15-23.

17. Compact septum polarizers with a circular output waveguide / A.A. Kirilenko, D.Yu. Kulik, L.A. Rud et al. // Fifth International Kharkov Symposium on Physics and Engineering of Microwaves, Milimeter and Submilimeter Waves. - Ukraine, Kharkov, 2004. - P. 686-688.

18. Mrnka M. Antenna range illuminator based on a septum polarizer and dual-mode horn / M.Mrnka, M.Pavlovic, Z.Raida // IEEE Antennas and Propagation Magazine. - 2016. - Vol. 58, № 4. - P. 82-86.

19. Wang X. Novel square/rectangle waveguide septum polarizer / X.Wang, X.Huang, X.Jin // IEEE International Conference on Ubiquitous Wireless Broadband. - China, Nanjing, 2010.

20. Compact X-band stepped-thickness septum polarizer / F.Dubrovka, S.Piltyay, O.Sushko et al. // IEEE 12th Int. Conf. on Antenna Theory and Techniques (ICATT*20). - Ukraine, Kharkiv, 2020. - P. 135-138.

21. Ultra-broadband low axial ratio corrugated quad-ridge polarizer / A.Tribak, A.Mediavilla, J.L. Cano et al. // European Microwave Conference (EuMC). - Italy, Rome, 2009. - P. 73-76.

22. Tikhonov $Y$. Comparison of two kinds of Ka-band circular polarisers for use in a gyro-travelling wave amplifier / Y.Tikhonov // IET Microwaves Antennas and Propagation. - 2016. - Vol. 10, № 2. - P. 147-151.

23. Compact-size polarization rotators on the basis of irises with rectangular slots / D.Yu. Kulik, L.P. Mospan, A.O. Perov, N.G. Kolmakova // Telecommunications and Radio Engeneering. - 2016. - Vol. 75, № 1. - P. 1-9.

24. Polarization plane rotation by arbitrary angle using D4 symmetrical structures / N.Kolmakova, A.Perov, V.Derkach, A.Kirilenko // IEEE Transactions on Microwave Theory and Techniques. - 2016. - Vol. 64, № 2. - P. 429-435.

25. Marcuvitz N. Waveguide handbook / N.Marcuvitz. - USA : Short Run Press Ltd., 1986. - 446 p.

\section{References:}

1. Yoneda, N., Miyazaki, R., Matsumura, I. and Yamato, M. (2000), «A design of novel grooved circular waveguide polarizers», IEEE Transactions on Microwave Theory and Techniques, Vol. 48, No. 12, pp. 2446-2452.

2. Kirilenko, A.A., Steshenko, S.O., Derkach, V.N. and Ostryzhnyi, Y.M. (2019), «A tunable compact polarizer in a circular waveguide», IEEE Transactions on Microwave Theory and Techniques, Vol. 67, No. 2, pp. 592-596.

3. Franco, M.J. (2011), «A high-performance dual-mode feed horn for parabolic reflectors with a stepped-septum polarizer in a circular waveguide», IEEE Antennas and Propagation Magazine, Vol. 53, No. 3, pp. 142-146.

4. Piltyay, S.I. (2017), «High performance extended C-band 3,4-4,8 GHz dual circular polarization feed system», XI International Conference on Antenna Theory and Techniques, Kyiv, Ukraine, pp. 284-287.

5. Agnihotri, I. and Sharma, S.K. (2019), «Design of a compact 3D metal printed Ka-band waveguide polarizer», IEEE Antennas and Wireless Propagation Letters, Vol. 18, No. 12, pp. 2726-2730.

6. Virone, G., Tascone, R., Peverine, O.A. et al. (2008), «Combined-phase-shift waveguide polarizer», IEEE Microwave and Wireless Components Letters, Vol. 18, No. 8, pp. 509-511.

7. Dubrovka, F.F. and Piltyay, S.I. (2013). «A novel wideband coaxial polarizer», IX International Conference on Antenna Theory and Techniques, Kyiv, Ukraine, pp. 473-474.

8. Kirilenko, A.A., Kulik, D.Yu., Pricolotin, S.A. et al. (2013), «Stepped approximation technique for designing coaxial waveguide polarizers», IX International Conference on Antenna Theory and Techniques, Odessa, Ukraine, pp. 470-472.

9. Piltyay, S.I., Bulashenko, A.V. and Demchenko, I.V. (2020), «Waveguide iris polarizers for Ku-band satellite antenna feeds», Journal of Nano- and Electronic Physics, Vol. 12, No. 5, pp. 05024-1-05024-5.

10. Bulashenko, A.V., Piltay, S.I. and Demchenko, I.V. (2020), «Analytical technique for iris polarizers development», IEEE International Conference on Problems of Infocommunications. Science and Technology (PIC S\&T), Kharkiv, Ukraine, pp. 471-476.

11. Piltyay S.I., Bulashenko, A.V. and Demchenko, I.V. (2013), «Compact polarizers for satellite information systems», IEEE International Conference on Problems of Infocommunications. Science and Technology (PIC S\&T), Kharkiv, Ukraine, pp. 317-322.

12. Bulashenko, A.V., Piltyay S.I. and Bykovsky, O.B. (2020), «Shyrokosmugovi poljaryzatory dlja suputnykovyh informacijnyh system», Materialy vseukrai'ns'koi' naukovo-praktychnoi' internet-konferencii' "Molod'v nauci: doslidzhennja, problemy, perspektyvy», Vinnytsia, pp. 365-368.

13. Zhu, Q.C., Williamson, A.G. and Neve, M.J. (2007), «Reactance of posts in circular waveguide», IEEE Transactions on Microwave Theory and Techniques, Vol. 55, No. 8, pp. 1685-1688.

14. Mospan, L.P., Kirilenko, A.A., Kulik, D.Yu. and Prikolotin, S.A. (2014), «Spectral properties of a rectangular wave guiding involving a pair of rectangular posts of equal heights», Telecommunications and Radio Engineering, Vol. 73, No. 1, pp. 1-17.

15. Deutschmann, B. and Jacob, A.F. (2020), «Broadband septum polarizer with triangular common port», IEEE Transactions on Microwave Theory and Techniques, Vol. 68, No. 2, pp. 693-700.

16. Dubrovka, F.F., Piltyay, S.I., Dubrovka, R.R. et al. (2020), «Optimum septum polarizer design for various fractional bandwidths», Radioelectronics and Communications Systems, Vol. 63, No. 1, pp. 15-23.

17. Kirilenko, A.A., Kulik, D.Yu., Rud, L.A. et al. (2004), «Compact septum polarizers with a circular output waveguide», Fifth International Kharkov Symposium on Physics and Engineering of Microwaves, Milimeter and Submilimeter Waves, Kharkov, Ukraine, pp. 686-688.

18. Mrnka, M., Pavlovic, M. and Raida, Z. (2016), «Antenna range illuminator based on a septum polarizer and dualmode horn», IEEE Antennas and Propagation Magazine, Vol. 58, No. 4, pp. 82-86. 
19. Wang, X., Huang, X. and Jin, X. (2010), «Novel square/rectangle waveguide septum polarizer», IEEE International Conference on Ubiquitous Wireless Broadband, Nanjing, China.

20. Dubrovka, F., Piltyay, S., Sushko, O. et al. (2020), «Compact X-band stepped-thickness septum polarizer», IEEE 12th Int. Conf. on Antenna Theory and Techniques (ICATT*20), Kharkiv, Ukraine, pp. 135-138.

21. Tribak, A., Mediavilla, A., Cano, J.L. and other (2009), «Ultra-broadband low axial ratio corrugated quad-ridge polarizer», European Microwave Conference (EuMC), Rome, Italy, pp. 73-76.

22. Tikhonov, Y. (2016), «Comparison of two kinds of Ka-band circular polarisers for use in a gyro-travelling wave amplifier», IET Microwaves Antennas and Propagation, Vol. 10, No. 2, pp. 147-151.

23. Kulik, D.Yu., Mospan, L.P., Perov, A.O. and Kolmakova, N.G. (2016), «Compact-size polarization rotators on the basis of irises with rectangular slots», Telecommunications and Radio Engeneering, Vol. 75, No. 1, pp. 1-9.

24. Kolmakova, N., Perov, A., Derkach, V. and Kirilenko, A. (2016), «Polarization plane rotation by arbitrary angle using D4 symmetrical structures», IEEE Transactions on Microwave Theory and Techniques, Vol. 64, No. 2, pp. $429-435$

25. Marcuvitz, N. (1986), Waveguide handbook, Short Run Press Ltd., USA, 446 p.

Булашенко Андрій Васильович - старший викладач кафедри теоретичних основ радіотехніки Національного технічного університету України «Київський політехнічний інститут імені Ігоря Сікорського».

Наукові інтереси:

- телекомунікації, радіоелектроніка;

- пристрої НВЧ та антени.

https://orcid.org/0000-0002-4987-4978.

E-mail: a.bulashenko@kpi.ua.

Пільтяй Степан Іванович - кандидат технічних наук, доцент кафедри теоретичних основ радіотехніки Національного технічного університету України «Київський політехнічний інститут імені Ігоря Сікорського».

Наукові інтереси:

- електродинаміка;

- пристрої НВЧ та антени.

https://orcid.org/0000-0002-6927-8663.

E-mail: s.piltiai@kpi.ua.

Калініченко Слізавета Ігорівна - студентка кафедри теоретичних основ радіотехніки Національного технічного університету України «Київський політехнічний інститут імені Ігоря Сікорського».

Наукові інтереси:

- пристрої НВЧ та антени.

https://orcid.org/0000-0001-9085-1201.

E-mail: kaliza@ukr.net.

Булашенко Олександр Васильович - студент Хіміко-технологічного коледжу Сумського державного університету.

Наукові інтереси:

- пристрої НВЧ та антени.

https://orcid.org/0000-0002-5648-6658.

E-mail: alex.bulashenko2020@gmail.com. 